DEPARTMENT OF THE INTERIOR

UNITED STATES GEOLOGICAL SURVEY

\title{
ARABILITY MAP OF THE PHOENIX AREA, ARIZONA
}

By U.S. Bureau of Reclamation and U.S. Department of Agriculture 